\title{
In-Vitro Analysis of Extracts of Fresh Fruits and their Precaps Against Pathogenic Microbes
}

\author{
Sunil Kumar Singh ${ }^{1}$, Chandan Prasad ${ }^{2 *}$, Shailendra Kumar Singh ${ }^{3}$ and Vinita Srivastava ${ }^{4}$ \\ ${ }^{1}$ Department of Botany, DAV College, Kanpur, U.P., India \\ ${ }^{2}$ Department of Chemistry, DAV College, Kanpur, U.P., India \\ ${ }^{3}$ Department of Botany, DAV College, Kanpur, U.P., India \\ ${ }^{4}$ Department of Chemistry, DAV College, Kanpur, U.P., India \\ "Corresponding Author: chandan_dav12@yahoo.in, Mob.No.919415439013
}

Available online at: www.isroset.org

Received: 13/Dec/2018, Accepted: 31/Dec/2018, Online: 28/Feb/2019

\begin{abstract}
Phytochemicals present in plants are of great significance to humans in various ways. They contribute life sustaining properties and have a potential to provide vigor against diseases viz. cancer and cardiovascular diseases. The objective of this analysis was to acquire data about the anti-microbial activity of fruits and vegetables against different pathogens viz. Escherichia coli, Pseudomonas aeruginosa, Bacillus subtilis. The extracts were prepared via solvent extraction method by dissolving different samples of fruits and vegetables in solvents viz. Acetone, Chloroform, $80 \%$ Methanol and 70\% Ethanol for 48 hours. These solvents were kept under dark condition for two days so that the solvent retains its efficiency. Samples were then subjected to Anti-microbial susceptibility test and the analysis revealed that pre-cap of Vitis vinifera (Black grapes) gave the best result against Pseudomonas aeruginosa with a diameter of $23.50 \mathrm{~mm}$. It was observed that the extract of Anthocephalus cadamba (Cadamba) gave better results when dissolved in polar solvents viz. 80\% Methanol and 70\% Ethanol than in Chloroform. Fresh extract of Manilkara zapota (chiku) gave results only when dissolved in Chloroform against all the three pathogens.
\end{abstract}

Keywords -- Antimicrobial activity, Manilkara zapota, Trigonella foenum-graecum, Vitis vinifera, Anthocephalus cadamba; Acetone, Chloroform, 80\% Methanol and 70\% Ethanol.

\section{INTRODUCTION}

An apple a day keeps the doctor away is a commonly learned expression from our early childhood, though it is not the apple but the substance which is present inside an apple that is what keeps the doctor away. A study suggests that the phyto-nutrients present in the apple helps reducing the cholesterol from our body. As per this study, funded by an apple industry group, published in the Journal of Functional Foods it says those who ate a daily apple over four weeks lowered 'bad' cholesterol also termed as low-density lipoprotein in the blood by 40 percent and thereby averting the risk of heart disease [1].

Doctors always recommend their patients to eat whole foods and for some undetermined reasons their patients tend to show astonishing recovery with a diet based on whole grain foods and vegetables and fresh fruits. Science has now found the answers to these hasty recoveries and has proven the fact that eating grains, vegetables, legumes, fruits, seeds and nuts in our daily diet has put a great impact in strengthening our immune system and health. In an average a tomato contains 10,000 phytochemicals and the regular consumption of tomato reduces cancer of the esophagus, oral cavity, stomach, colon, and rectum. This is based on two studies, the first comparing 2,709 cases of digestive tract cancer to 2,879 hospital admitted controls, and the second comparing 1,953 cases of colorectal cancer to 4,154 controls [2].

There are over 60 flavonoids in citrus fruits. These flavonoids have anti-inflammatory, antioxidant, anti-blood clotting, and antitumor properties. Sulfides in garlic and onions, diphiolthiones and isothiocyanate in cabbage and broccoli, curcumins in turmeric and ginger, phthalides in celery seed, and liminoids in citrus all stimulate glutathione S-transferase activity, which in turn has very powerful anticancer properties [3]. Even though there are immeasurable benefits of eating fruits and vegetables the graph of unhealthy diet is surpassing the diet plan of a common man's daily food habits.

According to The Times of India on an average, Indians consume 3.5 servings of fruits and vegetables per day which is an intake of upper and middle income groups on the contrary to 400 grams (or five daily servings with an average size of 80 grams) of fruits and vegetables recommended by World Health Organization. The trend in consumption pattern, however, varies from region to region with people 
living in south Indian cities consuming more fruits and vegetables as compared to those in the north.

However, our country at present ranks second in the production of fruits and vegetables in the world after China, a 2013 study conducted by Safola Life concluded that over 70 per cent of the urban Indian population is at the risk of being diagnosed with heart disease. This is mainly due to unhealthy eating habits, lack of physical activity and stress. Physical inactivity doubles the risk of cardiovascular disease, type-II diabetes and obesity.

Therefore, in present study the fresh fruit extracts and their pre-caps are tested in vitro against pathogenic microorganism to find out the antimicrobial efficacy of fruit and vegetables.

\section{MATERIAL AND METHODS}

The microbiological samples Escherichia coli, Pseudomonas aeruginosa and Bacillus subtilis were collected from Microbiology division of Shivam Dental Hospital, Kanpur, Uttar Pradesh, India. The isolates were identified according to published guidelines of Burneti et al. 1994. India. The bacterial strains were maintained on Mueller-Hinton agar (MHA) and Potato dextrose agar (PDA) plates respectively at $4{ }^{\circ} \mathrm{C}$.

\section{Test organism:}

Bacillus subtilis, a gram-positive, rod-shaped bacterium found in soil and gastrointestinal tract. It can form a tough, protective endospore, allowing it to tolerate extreme environmental conditions.

Pseudomonas aeruginosa, a gram-negative, rod-shaped bacterium that can cause diseases in plants and animals, including humans. It is a multi-drug resistant pathogen known for its intrinsically advanced antibiotic resistance mechanism.

Escherichia coli, a gram-negative facultative anaerobic, rodshaped, coliform bacterium commonly found in the lower intestine of endotherms. They can cause serious food poisoning though the strains which are harmless benefit their hosts by producing vitamin $\mathrm{K}_{2}$.

\section{Procurement of the fruits and vegetables:}

The procurement of the fruit and vegetables were done from grocery stores and vendors and some of the fruits were handpicked from gardens near MRD Life Sciences, Vibhuti Khand, Gomti Nagar, Lucknow.

\section{Preparation of Extract from fruits and vegetables: Sample preparation}

The fruits and vegetables were taken and washed with tap water and were cut into pieces and then the pieces were weighed, some part was kept separately under sun rays for drying.

\section{Extraction}

$4 \mathrm{gm}$ of sample was dissolved into $40 \mathrm{ml}$ of 4 different solvents. These solvents included Acetone, Chloroform, 80\% Methanol and 70\% Ethanol. After dipping the sample into the solvents each of them were kept under dark condition for 48 hours so that the chemicals retain their efficiency.

\section{Filtration}

After 48 hours, the solutions were filtered with the help of a funnel (appended with a filter paper), and were collected in a bowl. Then the bowls were kept inside the oven for the filtrate to dry $[4,5]$.

\section{Storage}

After the filtrate was dried Di-methyl sulfoxide (DMSO) was added which acts as a cryo-preserving agent, and the extract was stored in deep freezer under $-20^{0} \mathrm{C}$ conditions.

\section{Screening of Phytochemicals:}

\section{Anti-microbial Susceptibility Test (AST)}

Agar well diffusion method was used for the screening and analysis, the agar plate surface was inoculated by spreading a volume of the microbial inoculum over the entire agar surface. Then, a hole with a diameter of 6 to $8 \mathrm{~mm}$ was punched aseptically with a sterile cork borer or a tip, and a volume $(20-100 \mu \mathrm{L})$ of the antimicrobial agent that is our sample extract solution was introduced into the well. Then, agar plates were incubated for 24 hours at $35^{\circ} \mathrm{C}$ in the incubator $[6,7]$.

\section{RESULTS AND DISCUSSION}

\section{Extraction of secondary metabolites from fruits and vegetables :}

The extracts were prepared via method described in materials and methods and were stored under $-20^{\circ} \mathrm{C}$ in DMSO (Di-methyl sulfoxide) for further analysis.

\section{Anti-microbial susceptibility test}

Antibiotic sensitivity test was performed as described in materials and methods. The results of the extracts are shown in the following tables and figures below.

\section{Fresh and pre-cap Anthocephalus cadamba (Cadamba)}

Cadamba fruit extract showed a partial zone in fresh and pre-cap against the pathogens in all the plates as shown in the figure. 
Table 1. Zone of Inhibition of extracts of fresh ripened Anthocephalus cadamba (mm)

\begin{tabular}{|l|l|l|l|l|l|}
\hline S. No. & \multicolumn{1}{|c|}{ Pathogen } & \multicolumn{4}{c|}{ Zone of Inhibition (mm) } \\
\hline & & Acetone & $\mathbf{8 0 \%}$ Methanol & Chloroform & $\mathbf{7 0 \%}$ Ethanol \\
\hline 1. & Escherichia coli & $12.0 \mathrm{~mm}$ & $19.0 \mathrm{~mm}$ & $13.0 \mathrm{~mm}$ & $19.0 \mathrm{~mm}$ \\
\hline 2. & Pseudomonas aeruginosa & - & $16.0 \mathrm{~mm}$ & - & $18.0 \mathrm{~mm}$ \\
\hline 3. & Bacillus subtilis & $13.0 \mathrm{~mm}$ & $14.0 \mathrm{~mm}$ & $12.0 \mathrm{~mm}$ & $13.0 \mathrm{~mm}$ \\
\hline
\end{tabular}

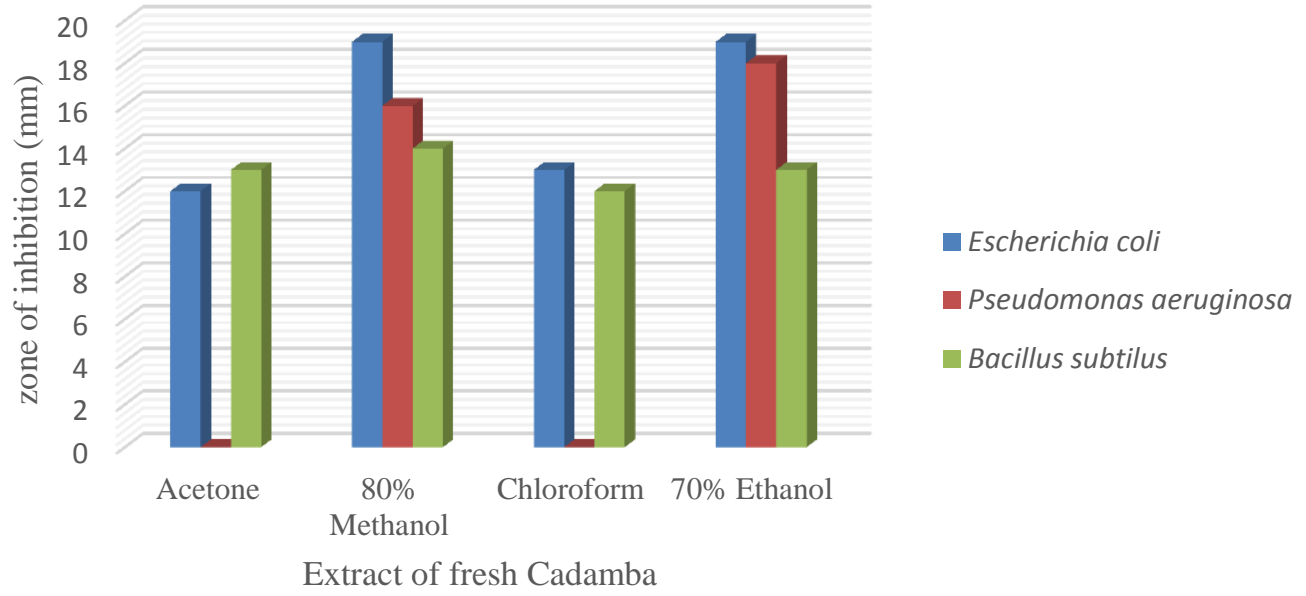

Figure 1. Graphical representation of values obtained in AST of fresh ripened Anthocephalus cadamba Table 2. Zone of Inhibition of extracts of pre-cap of ripened Anthocephalus cadamba(in mm)

\begin{tabular}{|c|c|c|c|c|c|}
\hline S. no. & Pathogen & \multicolumn{4}{|c|}{ Zone of Inhibition (mm) } \\
\hline & & Acetone & $\mathbf{8 0 \%}$ Methanol & Chloroform & 70\% Ethanol \\
\hline 1. & Escherichia coli & $12.0 \mathrm{~mm}$ & $16.0 \mathrm{~mm}$ & $13.0 \mathrm{~mm}$ & $17.0 \mathrm{~mm}$ \\
\hline 2. & Pseudomonas aeruginosa & $15.0 \mathrm{~mm}$ & $15.0 \mathrm{~mm}$ & $12.0 \mathrm{~mm}$ & $16.0 \mathrm{~mm}$ \\
\hline 3. & Bacillus subtilis & $14.0 \mathrm{~mm}$ & $15.0 \mathrm{~mm}$ & $14.0 \mathrm{~mm}$ & $21.0 \mathrm{~mm}$ \\
\hline
\end{tabular}

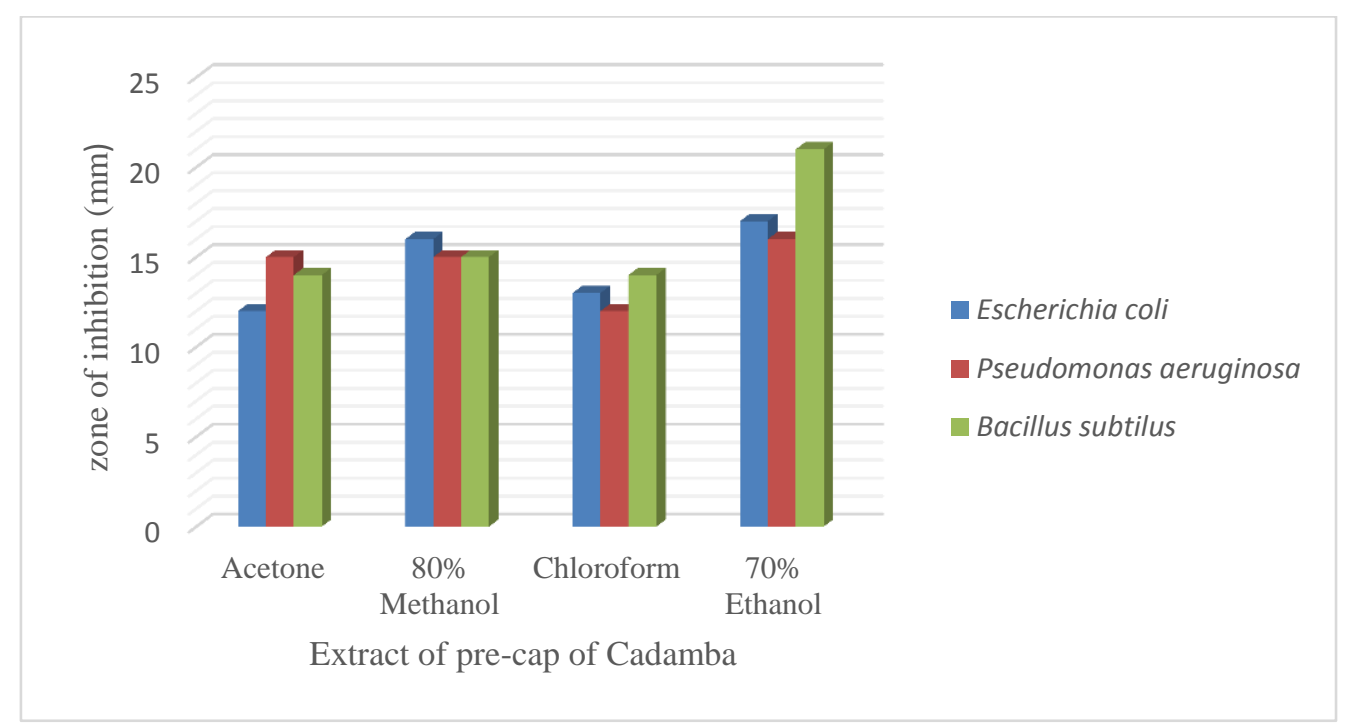

Figure 2. Graphical representation of values obtained in AST of pre-cap of ripened Anthocephalus cadamba 


\section{Fresh and pre-cap Manilkara zapota (chiku)}

Fresh Manilkara zapota (chiku) dissolved in chloroform showed a partial zone in the AST and the pre-cap showed results in the extract dissolved in $80 \%$ methanol, both fresh and pre-cap did not show any result in other solvents.

Table 3. Zone of Inhibition of extracts of fresh Manilkara zapota (chiku) (mm )

\begin{tabular}{|c|c|c|c|c|c|}
\hline S. No. & Pathogen & \multicolumn{4}{|c|}{ Zone of Inhibition (mm) } \\
\hline & & Acetone & $\mathbf{8 0 \%}$ Methanol & Chloroform & $\mathbf{7 0 \%}$ Ethanol \\
\hline 1. & Escherichia coli & - & - & $12.5 \mathrm{~mm}$ & - \\
\hline 2. & Pseudomonas aeruginosa & - & - & $12.5 \mathrm{~mm}$ & - \\
\hline 3. & Bacillus subtilis & - & - & $13.0 \mathrm{~mm}$ & - \\
\hline
\end{tabular}

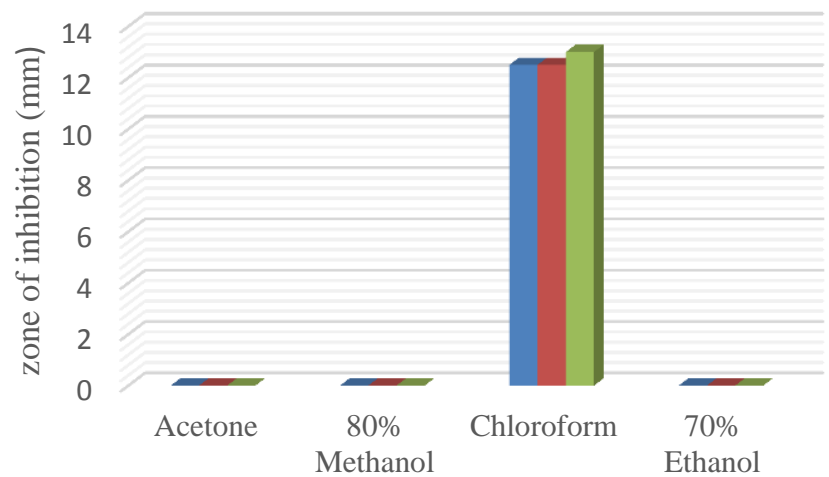

Escherichia coli

- Pseudomonas aeruginosa

Bacillus subtilus

Extract of fresh Sapodilla

Figure 3. Graphical representation of values obtained in AST of fresh Manilkara zapota

Table 4. Zone of Inhibition of extracts of Pre-cap of Manilkara zapota (in mm)

\begin{tabular}{|c|c|c|c|c|c|}
\hline S .no. & Pathogen & \multicolumn{4}{|c|}{ Zone of Inhibition (mm) } \\
\hline & & Acetone & $\mathbf{8 0 \%}$ Methanol & Chloroform & $\mathbf{7 0 \%}$ Ethanol \\
\hline 1. & Escherichia coli & - & $15.0 \mathrm{~mm}$ & - & - \\
\hline 2. & Pseudomonas aeruginosa & - & - & - & - \\
\hline 3. & Bacillus subtilis & - & $11.0 \mathrm{~mm}$ & - & - \\
\hline
\end{tabular}

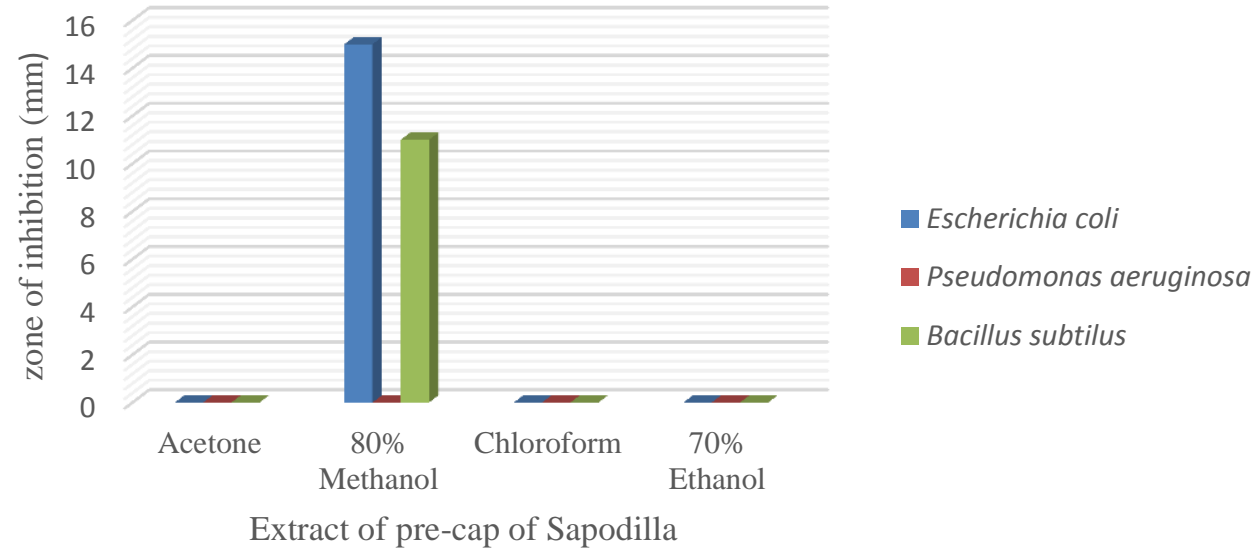

Figure 4. Graphical representation of values obtained in AST of pre-cap of Manilkara zapota 


\section{Fresh and pre-cap Trigonella foenum -graecum (Fenugreek)}

Fresh Fenugreek when tested for AST showed a partial zone in all the four solvents, better results were found in acetone. Maximum zone of inhibition was observed in the extract of $80 \%$ methanol against $E$. Coli.

Table 5. Zone of Inhibition of extracts of Trigonella foenum -graecum (Fenugreek)(mm)

\begin{tabular}{|c|c|c|c|c|c|}
\hline S. No. & Pathogen & \multicolumn{4}{|c|}{ Zone of inhibition (mm) } \\
\hline & & Acetone & $\mathbf{8 0 \%}$ Methanol & Chloroform & $\mathbf{7 0 \%}$ Ethanol \\
\hline 1. & Escherichia coli & $18.0 \mathrm{~mm}$ & $20.0 \mathrm{~mm}$ & $12.5 \mathrm{~mm}$ & $17.0 \mathrm{~mm}$ \\
\hline 2. & Pseudomonas aeruginosa & $17.0 \mathrm{~mm}$ & - & $14.0 \mathrm{~mm}$ & $16.0 \mathrm{~mm}$ \\
\hline 3. & Bacillus subtilis & $14.0 \mathrm{~mm}$ & $14.5 \mathrm{~mm}$ & $12.0 \mathrm{~mm}$ & $15.5 \mathrm{~mm}$ \\
\hline
\end{tabular}

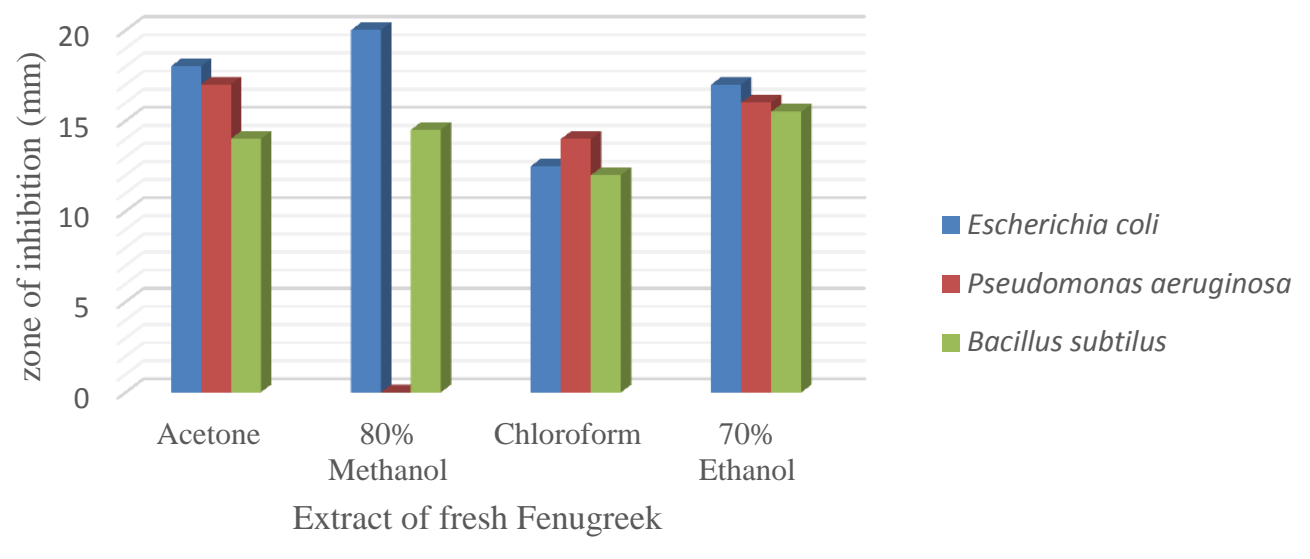

Figure 5. Graphical representation of values obtained in AST of fresh Trigonella foenum -graecum

Pre-cap showed a better result dissolved in the $70 \%$ ethanol solvent with maximum zone of inhibition observed against E. Coli.

Table 6. Zone of Inhibition of extracts of Pre-cap of Trigonella foenum -graecum (mm)

\begin{tabular}{|c|c|c|c|c|c|}
\hline S. no. & Pathogen & \multicolumn{4}{|c|}{ Zone of inhibition (mm) } \\
\hline & & Acetone & 80\% Methanol & Chloroform & 70\% Ethanol \\
\hline 1. & Escherichia coli & $12.5 \mathrm{~mm}$ & $17.5 \mathrm{~mm}$ & $13.5 \mathrm{~mm}$ & $18.5 \mathrm{~mm}$ \\
\hline 2. & Pseudomonas aeruginosa & $13.5 \mathrm{~mm}$ & $14.5 \mathrm{~mm}$ & $13.5 \mathrm{~mm}$ & $16.5 \mathrm{~mm}$ \\
\hline 3. & Bacillus subtilis & $12.5 \mathrm{~mm}$ & $14.0 \mathrm{~mm}$ & $11.5 \mathrm{~mm}$ & $18.0 \mathrm{~mm}$ \\
\hline
\end{tabular}

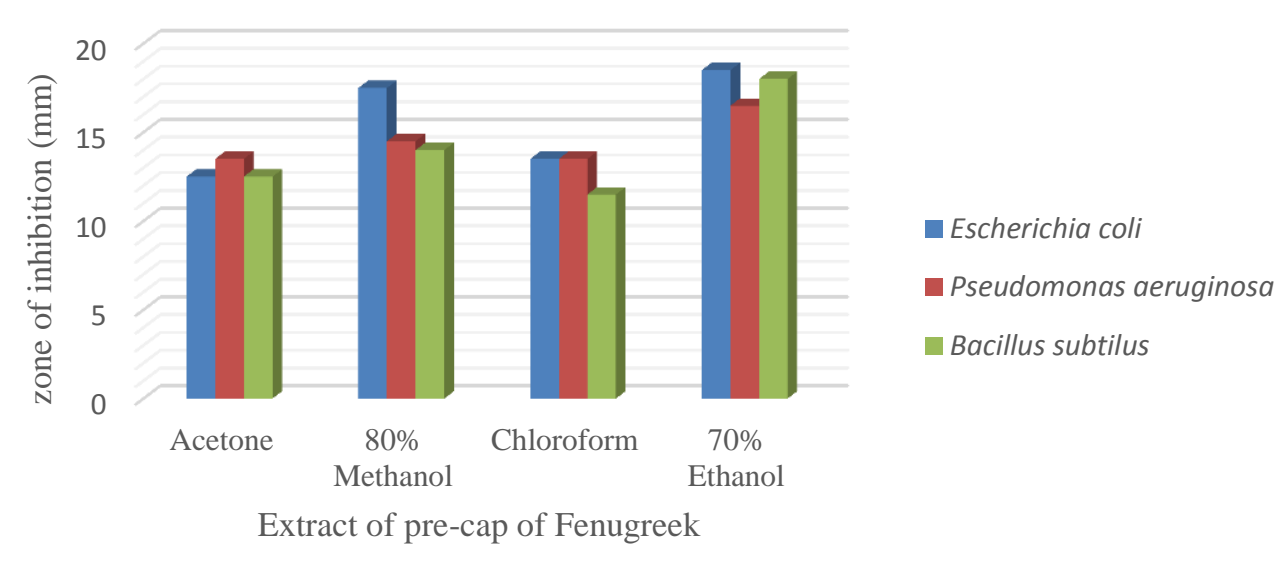

Figure 6. Graphical representation of values obtained in AST of pre-cap of Trigonella foenum -graecum 
Vitis vinifera (Black grapes)

A clear zone was observed in the AST performed with the extracts of black grapes and showed better results with the fruit dissolved in acetone solvent. Maximum zone of inhibition was observed in $80 \%$ methanol against Pseudomonas aeruginosa. Both clear and partial zones were observed in the pre-cap extracts, fruit dissolved in $80 \%$ methanol solvent showed much better result against all the three microbes.

Table 7. Zone of Inhibition of extracts of Vitis Vinifera (Black grapes)(mm)

\begin{tabular}{|c|c|c|c|c|c|}
\hline S. no. & Pathogen & \multicolumn{4}{|c|}{ Zone of inhibition (mm) } \\
\hline & & Acetone & $\mathbf{8 0 \%}$ Methanol & Chloroform & $\mathbf{7 0 \%}$ Ethanol \\
\hline 1. & Escherichia coli & $16.3 \mathrm{~mm}$ & $14.5 \mathrm{~mm}$ & - & $14.5 \mathrm{~mm}$ \\
\hline 2. & Pseudomonas aeruginosa & $18.5 \mathrm{~mm}$ & $21.0 \mathrm{~mm}$ & - & $18.0 \mathrm{~mm}$ \\
\hline 3. & Bacillus subtilis & $15.0 \mathrm{~mm}$ & - & - & $16.5 \mathrm{~mm}$ \\
\hline
\end{tabular}

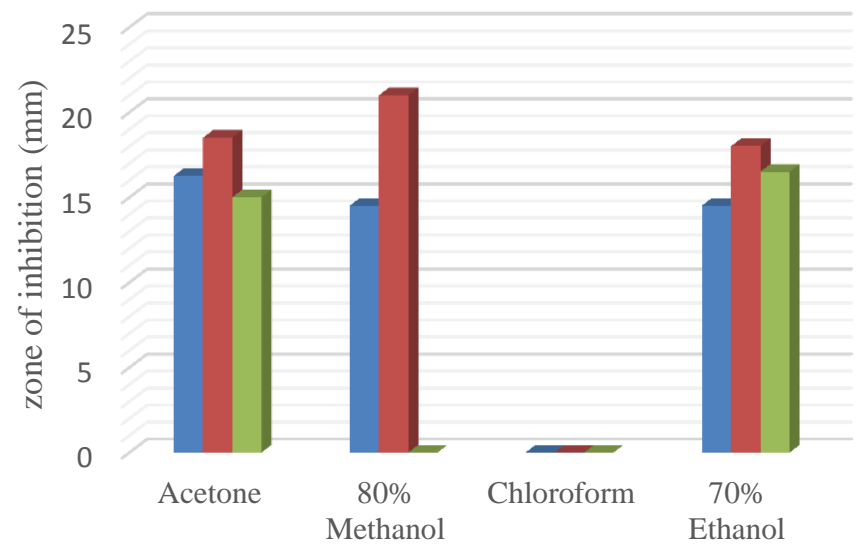

Escherichia coli

- Pseudomonas aeruginosa

Bacillus subtilus

Extract of Black grapes

Figure 7 . Graphical representation of values obtained in AST of Vitis vinifera (Black grapes)

Table 8 . Zone of Inhibition of extracts of Pre-cap Vitis vinifera (Black grapes)(mm)

\begin{tabular}{|c|c|c|c|c|c|}
\hline S. no. & Pathogen & \multicolumn{4}{|c|}{ Zone of inhibition (mm) } \\
\hline & & Acetone & $\mathbf{8 0 \%}$ Methanol & Chloroform & $\mathbf{7 0 \%}$ Ethanol \\
\hline 1. & Escherichia coli & - & $19.5 \mathrm{~mm}$ & - & $16.5 \mathrm{~mm}$ \\
\hline 2. & Pseudomonas aeruginosa & - & $23.5 \mathrm{~mm}$ & - & - \\
\hline 3. & Bacillus subtilis & - & $21.5 \mathrm{~mm}$ & - & $12.5 \mathrm{~mm}$ \\
\hline
\end{tabular}

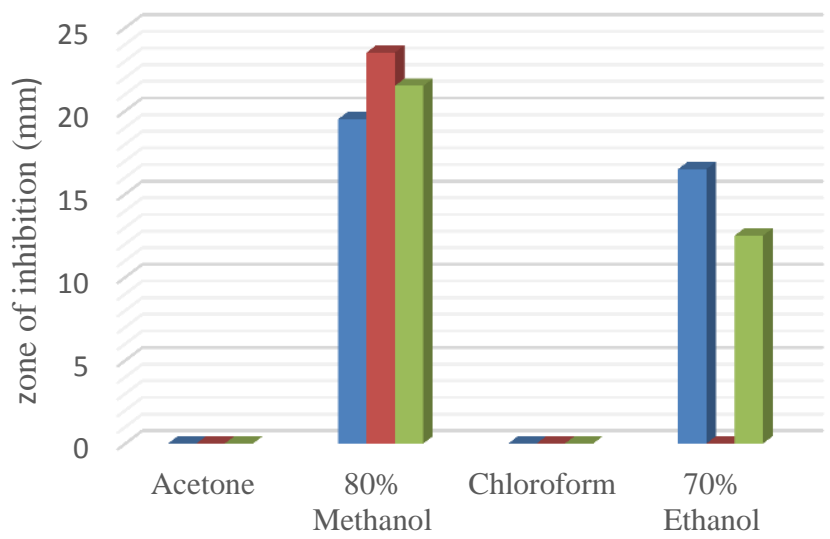

Escherichia coli

- Pseudomonas aeruginosa

Bacillus subtilus

Pre-cap of Black grapes

Figure 8. Graphical representation of values obtained in AST of pre-cap of Vitis vinifera (Black grapes) 


\section{CONCLUSION AND FUTURE SCOPE}

This research was undertaken with an objective to analyze different phytochemicals present in the various fruits and vegetables and their potential in the inhibition of the growth against the pathogens viz. Escherichia coli, Pseudomonas aeruginosa, Bacillus subtilis. In this work, extracts were prepared with the solvent extraction method and various fruits and vegetables were used for the analysis.

The results revealed that the extraction process was effective in mining out the phytochemicals present in the sample which was confirmed via Anti-microbial susceptibility test; both fresh and pre-cap of samples were used in some cases to maintain the certainty of the results obtained. Four different solvents were used based on polarity and $40 \mathrm{ml}$ of a solvent was used to dissolve $4.0 \mathrm{gms}$ of sample. The dilution factor used during the AST was 4:1 i.e. $400 \mu \mathrm{L}$ DMSO: $100 \mu \mathrm{L}$ of extract of sample.

AST revealed that the samples showed a partial zone of inhibition in almost all the samples, and in some cases, it showed clear zones except in sapodilla which only gave results in sample dissolved in Chloroform. Best results were obtained in the pre-cap of Vitis vinifera (Black grapes) with a diameter of $23.5 \mathrm{~mm}$ against Pseudomonas aeruginosa.

\section{REFERENCES}

[1] S.R. Deshmukh, D.S. Ashrit, \& B.A. Patil, " Extraction and Evaluation of Indole Alkaloids from Rauwolfia serpentina for their Antimicrobial and Antiproliferative Activities", International Journal of Pharmacy and Pharmaceutical Sciences, Vol.4, Issue., 5, pp. 329-334, 2012.

[2] Li. Fu, W. Lu, and X. Zhou, "Phenolic Compounds and In Vitro Antibacterial and Antioxidant Activities of Three Tropic Fruits: Persimmon, Guava, and Sweetsop", BioMed Research International, Article ID: 4287461, 9 pages, 2016.

[3] S. Sathyanarayanan, P. Selvam, A. Jose, R.M. George, K.G. Revikumar and J. Neyts, "Preliminary Phytochemical Screening and Study of Antiviral Activity and Cytotoxicity of Wrightiatinctoria," International Journal of Chemical Sciences, Vol.7, pp. 01-05, 2009.

[4] N.S. Topare, S.J. Raut, V.C. Renge, S.V. Khedkar, Y.P. Chavan, and S.L. Bhagat, "Extraction of Oil from Algae by Solvent Extraction and Oil Expeller Method", International Journal of Chemical Sciences, Vol. 9, Issue 4, pp. 1746-1750, 2011.

[5] S.A. Wagay, S.D. Dwivedi, M. Sharma, J. Tripathi, and M. Ahmad, "Antimicrobial Activity of Catharanthus roseus" Chemistry and Materials Research, Vol. 3, Issue 9, pp. 61-64, 2013.

[6] S. Magaldi, S. Mata-Essayag, De. Hartung, and C. Capriles, "Well Diffusion for Antifungal Susceptibility Testing”, International Journal of Infectious Diseases, Vol. 8, pp. 39-45, 2004.

[7] C.Valgas, S.M. De Souza, and E.F.A. Samania, 'Screening Methods to Determine Antibacterial Activity of Natural Products", Journal of Microbiology, Vol. 38, pp. 369-380, 2007. 